CHRONIC OBSTRUCTIVE PULMONARY DISEASE

\title{
Enhanced bronchial expression of vascular endothelial growth factor and receptors (Flk-1 and Flt-1) in patients with chronic obstructive pulmonary disease
}

\author{
A R Kranenburg, W I de Boer, V K T Alagappan, P J Sterk, H S Sharma
}

Thorax 2005;60:106-113. doi: 10.1136/thx.2004.023986

See end of article for authors' affiliations

\section{Correspondence to:}

H S Sharma, Institute of Pharmacology, Erasmus MC, University Medical Center, Dr Molewaterplein 50, 3015 GE Rotterdam, The Netherlands;

h.sharma@erasmusmc.nl

Received 19 May 2004 Accepted 15 August 2004
Background: Ongoing inflammatory processes resulting in airway and vascular remodelling characterise chronic obstructive pulmonary disease (COPD). Vascular endothelial growth factor (VEGF) and its receptors VEGFR-1 (Flt-1) and VEGFR-2 (KDR/Flk-1) could play a role in tissue remodelling and angiogenesis in COPD.

Methods: The cellular expression pattern of VEGF, Flt-1, and KDR/Flk-1 was examined by immunohistochemistry in central and peripheral lung tissues obtained from ex-smokers with COPD (forced expiratory volume in 1 second $\left(\mathrm{FEV}_{1}\right)<75 \%$ predicted; $\mathrm{n}=14$ ) or without COPD $\left(\mathrm{FEV}_{1}>85 \%\right.$ predicted; $n=14$ ). The immunohistochemical staining of each molecule was quantified using a visual scoring method with grades ranging from 0 (no) to 3 (intense).

Results: VEGF, Flt-1, and KDR/Flk-1 immunostaining was localised in vascular and airway smooth muscle (VSM and ASM) cells, bronchial, bronchiolar and alveolar epithelium, and macrophages. Pulmonary endothelial cells expressed Flt- 1 and KDR/Flk-1 abundantly but not VEGF. Bronchial VEGF expression was higher in microvascular VSM cells and ASM cells of patients with COPD than in patients without COPD (1.7 and 1.6-fold, $p<0.01$, respectively). VEGF expression in intimal and medial VSM (1.7 and 1.3-fold, $\mathrm{p}<0.05$ ) of peripheral pulmonary arteries associated with the bronchiolar airways was more intense in COPD, as was VEGF expression in the small pulmonary vessels in the alveolar region (1.5 and 1.7-fold, $\mathrm{p}<0.02$ ). In patients with COPD, KDR/Flk- 1 expression was enhanced in endothelial cells and in intimal and medial $\operatorname{VSM}(1.3,1.9$ and 1.5-fold, $\mathrm{p}<0.02)$ while endothelial Flt-1 expression was 1.7 times higher $(p<0.03)$. VEGF expression was significantly increased in bronchiolar and alveolar epithelium as well as in bronchiolar macrophages (1.5-fold, $\mathrm{p}<0.001)$. The expression of VEGF in bronchial VSM and mucosal microvessels as well as bronchiolar epithelium was inversely correlated with $\mathrm{FEV}_{1}(r<-0.45 ; \mathrm{p}<0.01)$. Conclusions: VEGF and its receptors Flt-1 and KDR/Flk-1 may be involved in peripheral vascular and airway remodelling processes in an autocrine and/or paracrine manner. This system may also be associated with epithelial cell viability during airway wall remodelling in COPD.

\footnotetext{
C
} hronic obstructive pulmonary disease (COPD) is a disease state characterised by airflow limitation that is not fully reversible, usually progressive, and associated with an abnormal inflammatory response of the lungs in response to noxious particles and gases. ${ }^{1}$ COPD is a major health problem with cigarette smoking as its main cause. One important pathological feature of COPD is chronic airway inflammation characterised by an influx of inflammatory cells-predominantly neutrophils, macrophages and CD8+ T lymphocytes -in the lumen and wall of the bronchial and bronchiolar airways and parenchyma. ${ }^{2-4}$ Furthermore, several studies have reported a thickened bronchiolar wall and airway remodelling with peribronchiolar fibrosis, an increase in airway smooth muscle (ASM) mass, and emphysema. ${ }^{356}$

Vascular abnormalities have been associated with the development of COPD. ${ }^{78}$ Wright et al found an increase in wall area of small $(<500 \mu \mathrm{m})$ pulmonary vessels by intimal thickening in patients with mild to moderate COPD and medial thickening in severe cases as well, which was correlated with a decline in forced expiratory volume in l second $\left(\mathrm{FEV}_{1}\right) .^{79}$ Furthermore, recent observations have indicated that muscular pulmonary and bronchiolar arteries have increased adventitial infiltration of CD8+ T lymphocytes and have intimal thickening that is correlated with the amount of total collagen deposition. ${ }^{8}{ }^{10}$ In addition, emphysema may lead to loss of the pulmonary vascular bed and induce angiogenesis. ${ }^{11}$ Little is known, however, about the molecular mechanisms underlying these processes in the context of COPD.

One of the potent proteins involved in vascular remodelling is vascular endothelial growth factor (VEGF). The VEGF family currently comprises six members (VEGF-A to F), of which the originally identified VEGF- $\mathrm{A}_{165}$ variant is the predominant form of five additional spliced variants. ${ }^{12}$ VEGFs are heparin binding proteins and act via their high affinity transmembrane receptors VEGFR-1 (Flt-1) and VEGFR-2 (KDR/Flk-1). The receptors belong to the family of tyrosine kinases and are predominantly expressed by endothelial and epithelial cells. ${ }^{12}$ VEGF promotes an array of responses in the endothelium including hyperpermeability, endothelial cell proliferation, and angiogenesis with new vessel tube formation in vivo. ${ }^{12}{ }^{13}$ VEGF expression can be induced under a number of pathophysiological conditions including pulmonary hypoxia and pulmonary hypertension with increased sheer stress. ${ }^{13}{ }^{14}$ Both hypoxia and pulmonary hypertension are pathological features often seen in patients with advanced COPD. ${ }^{2}$ We hypothesise that increased VEGF

Abbreviations: ASM, airway smooth muscle; COPD, chronic obstructive pulmonary disease; $\mathrm{FEV}_{1}$, forced expiratory volume in 1 second; TGF- $\beta_{1}$, transforming growth factor $\beta_{1}$; VEGF, vascular endothelial growth factor; VSM, vascular smooth muscle 
expression, perhaps under the influence of hypoxia inducible transcription factors, may contribute to increased and abnormal proliferation of endothelial and vascular smooth muscle (VSM) cells in pulmonary vessels leading to vascular remodelling.

Although the role of VEGF in the vascular biology has been studied thoroughly, it has become clear that VEGF and its receptor system are also involved in various other cellular events including epithelial proliferation and survival and the recruitment of mast cells, neutrophils, and macrophages to sites of fibrosis. ${ }^{13} 1516$ Recent studies indicate that VEGF is expressed in the lung by bronchiolar, submucosal, glandular and alveolar type I and II epithelial cells, alveolar macrophages, ASM and VSM cells, as well as myofibroblasts in fibrotic lung lesions. ${ }^{1417} 18$

In order to assess the role of VEGF and its receptors VEGFR-1 (Flt-1) and VEGFR-2 (KDR/Flk-1) in the pathophysiology of COPD, we first examined the expression of VEGF-A, Flt-1, and KDR/Flk-1 in central and peripheral lung tissue from ex-smokers with or without COPD. We also investigated the relationship of lung function with the expression of VEGF and its receptors.

\section{METHODS}

\section{Selection of patients}

Central and peripheral lung tissues were obtained from current or ex-smokers undergoing lobectomy or pneumonectomy for lung cancer. Fourteen subjects with COPD ( $\mathrm{FEV}_{1}$ $<75 \%$ predicted) and 14 subjects without COPD ( $\mathrm{FEV}_{1}>84 \%$ predicted) were included as previously described. ${ }^{19-21} 23$ Total lung capacities (TLC) were not below normal levels (TLC $>80 \%$ predicted). None of the patients had an upper respiratory tract infection and they did not receive antibiotics perioperatively. No patients had received glucocorticosteroids during the 3 month period before resection; four patients received glucocorticosteroids perioperatively. Based on all these criteria, subjects with COPD could not be subdivided into patients with either chronic bronchitis or emphysema alone. Clinical data are given in table 1. Subjects were excluded if the obstruction of the central bronchi was due to the tumour, if diffuse pulmonary inflammation or fibrosis was present, or if no tissue free from tumour could be obtained. The patients in the two groups had participated in a larger research project, part of which has been published previously. ${ }^{19-21}$ The medical ethics committee of LUMC approved the study.

The lung tissue specimens used in this study were obtained from the archival collection at the Department of Pathology (LUMC, Leiden, NL). The specimens were routinely fixed in $10 \%$ neutral buffered formalin by inflation-immersion fixation and embedded in paraffin for histopathological examination and immunohistochemistry.

\section{Immunohistochemistry}

Paraffin sections ( $4 \mu \mathrm{m}$ thick) of the lung tissues were cut and mounted on silane coated glass slides. Immunohistochemistry was performed using a method described elsewhere. ${ }^{20} 22{ }^{23}$ Briefly, after deparaffinisation in xylene and rehydration through graded alcohol, the slides were rinsed with phosphate buffered saline (PBS). Endogenous peroxidase was blocked with $0.3 \%$ hydrogen peroxidase. For VEGF, VEGFR-1, VEGFR-2 and Ki-67 staining, slides were pretreated by boiling in citrate buffer $(10 \mathrm{mM}, \mathrm{pH}=6.0)$ for 10 minutes in a microwave oven. The sections were preincubated with $10 \%$ normal goat serum diluted in $5 \%$ bovine serum albumin (BSA) in PBS $(\mathrm{pH}=7.4)$ and then incubated for 30 minutes at room temperature with affinity purified rabbit polyclonal VEGF antibody in a dilution of $\mathrm{l}: 200 \mathrm{v} / \mathrm{v}$. The VEGF antibody used was raised against a 20 amino acid synthetic peptide corresponding to residues 1-20 of the amino terminus of human VEGF (Santa Cruz Biotechnology Inc, Santa Cruz, CA, USA). A different series of slides was incubated with a rabbit polyclonal antibody against a synthetic peptide corresponding to aa 1312-1328 of human Flt-1 (Neomarkers RB-1526, Fremont, CA, USA) in a dilution of $1: 100 \mathrm{v} / \mathrm{v}$. For VEGFR-2, a rabbit polyclonal antibody against amino acids 1326-1345 of mouse KDR/ Flk-1 (Neomarkers RB-1527) in a dilution of 1:200 v/v was used. To examine proliferation of cells in the airways an antibody against Ki-67 (Dako Corporation, Glostrup, Denmark) of $1: 400 \mathrm{v} / \mathrm{v}$ at $4^{\circ} \mathrm{C}$ overnight was used as a marker. Consecutive tissue sections were also stained with a monoclonal mouse anti-human alpha-smooth muscle actin ( $\alpha$-SMA) antibody (clone lA4; Biogenex, San Ramon, USA) in a dilution of $1: 1000 \mathrm{v} / \mathrm{v}$. The optimal dilution of the first antibody was identified by examining the intensity of staining obtained with a series of dilutions of the antibody from 1:50 to 1:1000. Negative controls were prepared by omission of the primary antibody.

After washing with Tris-base buffered saline (TBS, $\mathrm{pH}=7.4$ ) the test and control slides were incubated for 15 minutes with Powervision post-antibody blocking solution (Immunovision Technologies, Daly City, CA, USA). The slides were then washed and incubated with Powervision polymerised horseradish peroxidase conjugates (Immunovision Technologies) and the sections were stained with 3,3'diaminobenzidine tetrahydrochloride (Sigma, Zwijndrecht, NL) as chromogen, counterstained with Mayer's haematoxylin, and visualised with light microscopy.

\section{Quantitative scoring analysis of immunohistochemistry}

Before screening, sections were coded so that the observers were unaware of the clinical details of the case under study. Expression of VEGF, Flt-1, and KDR/Flk-1 was analysed semiquantitatively using a visual scoring method with grades ranging from 0 to $3(0=$ no staining; $1=$ moderate staining; $2=$ intense staining; $3=$ very intense staining) as previously described. $^{8192023}$ The entire section of a tissue block was investigated and scored at the same magnification. The staining intensity of VEGF, Flt-l, and KDR/Flk-l in the bronchial and bronchiolar airways as well as the alveolar parenchyma was scored blindly by two independent observers who were unaware of the clinical data of the case under

Table 1 Clinical characteristics of study subjects

\begin{tabular}{lllllll}
\hline Group & Sex (M/F) & Age & $\begin{array}{l}\text { Smoking } \\
\text { (pack years) }\end{array}$ & $\begin{array}{l}\mathrm{FEV}_{\mathbf{1}} \\
\text { (\% predicted) }\end{array}$ & $\begin{array}{l}\mathrm{FEV}_{\mathbf{1}} / \mathrm{FVC} \\
(\%)\end{array}$ & $\begin{array}{l}\text { Steroid } \\
\text { treatment }\end{array}$ \\
\hline $\begin{array}{l}\text { Non-COPD } \\
\text { COPD }\end{array}$ & $10 / 4$ & $64(3.7)$ & $42(7.7)$ & $101(3.3)$ & $0.72(0.02)$ & None \\
p value & $14 / 0$ & $64(2.3)$ & $44(0.8)$ & $63(2)$ & $0.54(0.02)$ & 4 \\
\hline
\end{tabular}

Data shown as mean (SD) values.

COPD, chronic obstructive pulmonary disease; $\mathrm{FEV}_{1}$, forced expiratory volume in 1 second, FVC, forced vital capacity. 

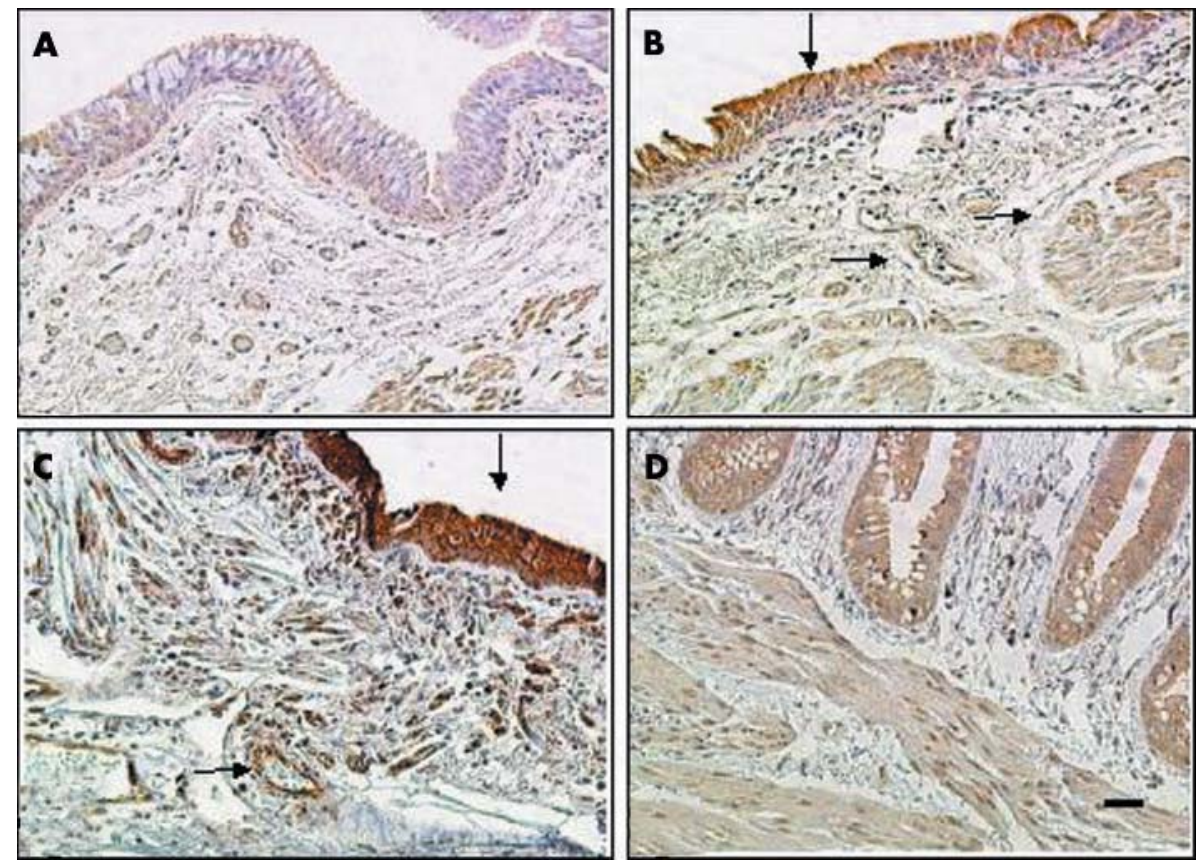

Figure 1 Immunohistochemical localisation of (A, B) VEGF, (C) KDR/Flk-1, and (D) Flt-1 in bronchial tissues from non-COPD (ex-) smoking subjects (A) and patients with COPD (B, C, D). Immunoreactive VEGF, KDR/Flk-1, and Flt-1 were localised in bronchial epithelial cells, airway smooth muscle (ASM) cells, and in macrophages, endothelial and vascular smooth muscle (VSM) cells. Colour was developed with 3,3-diaminobenzidine tetrahydrochloride (DAB) as chromogen (brown colour) and counterstained with Mayer's haematoxylin. Arrows indicate sites of positivity for VEGF, Flt-1 or KDR/Flk-1. Original magnification $\times 100$; scale bar $=50 \mu \mathrm{m}$.

study. Errors within and between observers were examined by correlating the expression scores using Pearson's analysis and a very high correlation ranging from 0.8 to 0.9 was obtained.

In the bronchial airways staining was assessed in the bronchial epithelium, mucosal microvasculature, submucosal bronchial wall vessels, ASM cells, and macrophages in the bronchial airway wall. In peripheral lung tissues the staining of VEGF and receptors was analysed in the bronchiolar and alveolar epithelium, bronchiolar ASM cells, and bronchiolar and alveolar macrophages. The vasculature in the peripheral lung was further subdivided into the larger pulmonary vessels associated with the bronchiolar airways and smaller vessels situated within the alveolar parenchyma. In each the VEGF and receptor staining of endothelial, intimal, and medial VSM cells was assessed. Since transforming growth factor- $\beta_{1}\left(\right.$ TGF- $\left.\beta_{1}\right)$ may also induce VEGF expression in epithelial cells, ${ }^{25}{ }^{26}$ we examined the correlation between the epithelial VEGF expression in this study and the epithelial TGF- $\beta_{1}$ expression from one of our previous studies. ${ }^{20}$ In both studies the same patient groups were used and the staining was performed on adjacent or near sections.

\section{Statistical analysis}

Data were analysed for statistical significance using the unpaired two-tailed Student's $t$ test and the non-parametric Mann-Whitney test where appropriate. Data on the expression of VEGF and its receptors were expressed as mean (SE). The staining of VEGF and its receptors for different compartments was correlated with $\mathrm{FEV}_{1}$ using Pearson's correlation analysis. Differences with $p$ values of $\leqslant 0.05$ were considered statistically significant.

\section{RESULTS}

\section{Clinical characteristics}

The clinical and lung function characteristics of all subjects included in the study are shown in table 1. As defined, the
COPD group had decreased $\mathrm{FEV}_{1}$ and $\mathrm{FEV}_{\mathrm{l}} / \mathrm{FVC}$ values $(\mathrm{p}<0.001)$, as has been described previously. ${ }^{19-23}$ The subjects in the two groups did not differ significantly in age and smoking status (pack years) or steroid use.

\section{Immunolocalisation of VEGF, Flt-1, and KDR/Flk-1 Bronchial airways}

Examples of VEGF expression in the central airways of nonCOPD and COPD subjects are shown in fig $1 \mathrm{~A}$ and $\mathrm{B}$, while fig $\mathrm{IC}$ and D (both taken from COPD subjects) show the VEGF receptors and KDR/Flk-1, Flt-1 respectively. Within the airways, VEGF, KDR/Flk-1 and Flt- 1 were localised in the bronchial epithelium and ASM cells, bronchial microvasculature of the mucosa and submucosa, and on inflammatory cells (predominantly macrophages) in all subjects (fig 1A-D). In the vessel wall, VSM cells were positive for VEGF, Flt-1, and KDR/Flk-1 while endothelial cells did not stain for VEGF protein but were positive for Flt- 1 and KDR/Flk-1 (fig l).

To assess the intensities of VEGF, Flt-1, and KDR/Flk-1 expression in various bronchial airway compartments, a visual scoring method was used as previously described. ${ }^{8} 192023$ VEGF expression was higher in the bronchial ASM cells of COPD patients than in those of non-COPD subjects (1.6-fold, $\mathrm{p}<0.01$ ) but not in bronchial epithelial cells and macrophages (fig $2 \mathrm{~A}$ ). In the central airways of patients with COPD, VEGF staining was more intense in the VSM microvasculature of the bronchial mucosal (lamina propria) $(1.7$-fold, $\mathrm{p}<0.001)$ and bronchial VSM in the submucosa ( 1.4 -fold, $\mathrm{p}<0.01$, fig $2 \mathrm{~A}$ ) than in non-COPD subjects. No significant differences were observed in the levels of expression of KDR/Flk-1 and Flt- 1 between COPD and non-COPD subjects (fig $2 \mathrm{~B}$ and $\mathrm{C}$, respectively). In all subjects VEGFR-2 (KDR/Flk-1) expression was more intense than VEGFR-1 (Flt-1) expression, except in the endothelial cells of bronchial microvessels and on bronchial macrophages which were comparable (fig 2B and C). 

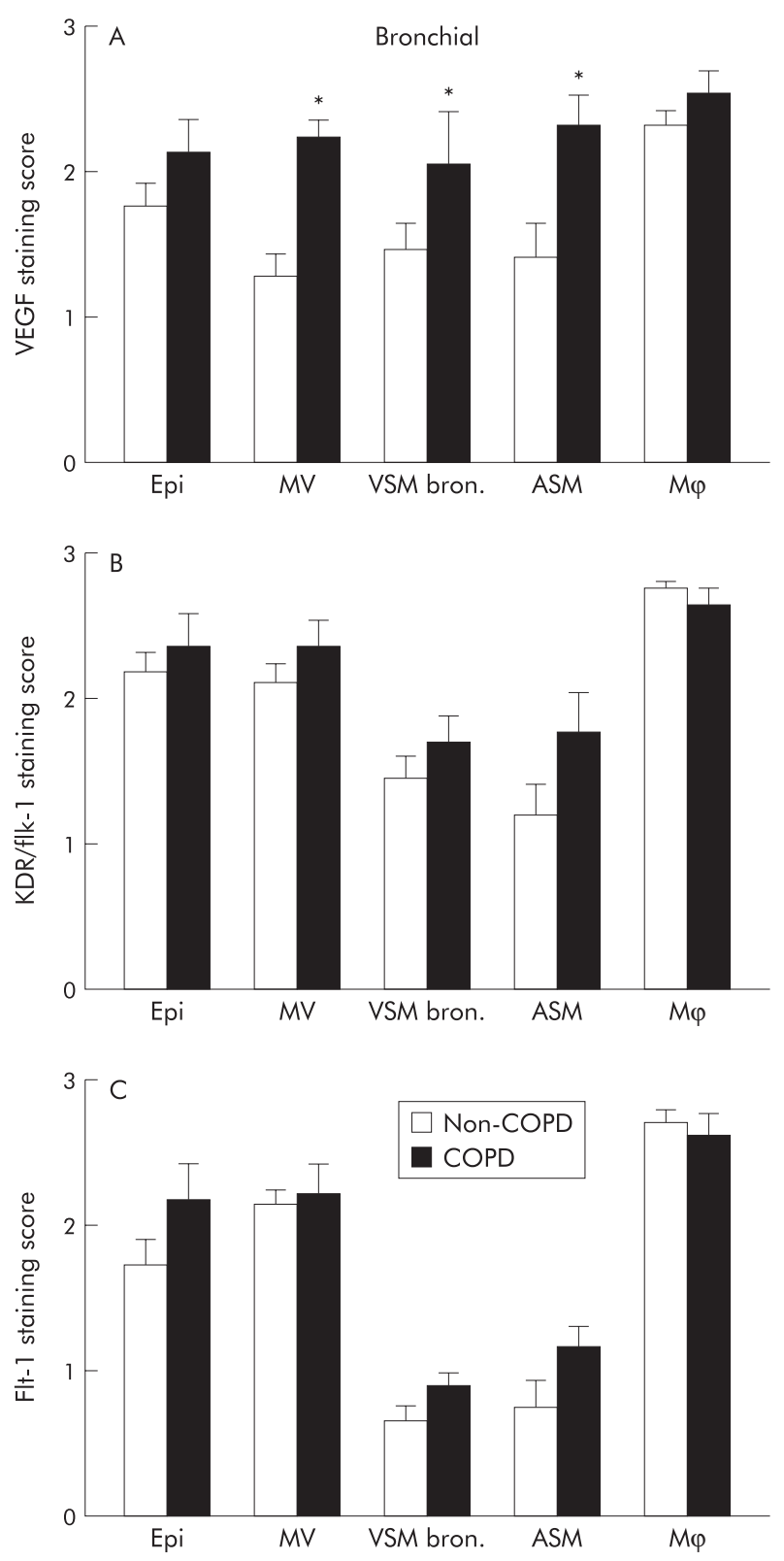

Figure 2 Expression of (A) VEGF, (B) KDR/Flk-1 and (C) Flt- 1 protein in different cell types in bronchial airways using visual scoring. The immunostaining score ranges from 0 (no staining) to 3 (very intense staining). Open and closed bars represent mean data from subjects without and with COPD, respectively. Data are presented as mean (SE). Asterisk indicates a significant difference $(p<0.05$, Student's $t$ test) compared with non-COPD subjects. Epi, bronchial epithelium; MV, bronchial microvessels in the mucosa; VSM bron, bronchial vascular smooth muscle cells in the submucosa; ASM, airway smooth muscle; $M \phi$, macrophages.

\section{Bronchiolar airways}

Figure 3 shows peripheral lung tissue from non-COPD and COPD subjects stained for VEGF (fig $3 \mathrm{~A}$ and $\mathrm{B}$ ), KDR/Flk-1 (fig $3 \mathrm{C}$ and $\mathrm{D}$ ), and Flt-1 (fig $3 \mathrm{E}$ and $\mathrm{F}$ ). In bronchiolar epithelial cells VEGF (1.5-fold, $\mathrm{p}<0.001$, fig 4A) and Flt-1 expression ( 1.4 -fold, $\mathrm{p}<0.04$, fig $4 \mathrm{C}$ ) were increased in COPD patients compared with non-COPD subjects whereas the staining for KDR/Flk-1 was unchanged in both patient groups (fig 4B). ASM cells showed slightly increased VEGF expression in the bronchiolar region $(1.3$-fold, $\mathrm{p}<0.05)$, whereas the expression of both the receptors remained unchanged in the two patient groups. However, the expression of KDR/Flk- 1 was more intense than Flt- 1 in all patients (fig $4 \mathrm{~B}$ and $\mathrm{C}$ ). The increase in the expression of VEGF in the larger pulmonary arteries associated with the bronchiolar airways in the intimal and medial VSM cells was 1.7 -fold and 1.3 -fold, respectively $(\mathrm{p}<0.05$, fig $4 \mathrm{~A})$ for COPD and control subjects, while endothelial cells did not express VEGF. KDR/ Flk-1 expression was enhanced in endothelial cells and intimal and medial VSM cells (1.3, 1.9 and 1.5-fold, respectively, $\mathrm{p}<0.02$, fig $4 \mathrm{~B})$; the corresponding value in endothelial cells for Flt-1 expression was 1.7-fold $(p<0.03$, fig 4C). In both patient groups the intimal VSM cells stained 2-3 times less intensely than medial VSM cells for VEGF, Flt1, and KDR/Flk-1. Moreover, vascular Flt-1 expression was lower than KDR/Flk-1 and VEGF expression in each of the investigated vessel wall areas $(\mathrm{p}<0.002$, fig 4$)$. VEGF staining in bronchiolar macrophages ( 1.5 -fold, $p<0.001$, fig $4 \mathrm{~A}$ ) was higher in COPD subjects than in non-COPD subjects, whereas the staining on macrophages of Flt- 1 or KDR/Flk- 1 expression in bronchiolar airways as well as VEGF, Flt-1, or KDR/Flk-1 in the alveolar region remained unchanged (fig 5).

\section{Alveolar parenchyma}

Staining of alveolar epithelial cells (type I and II) for COPD was more intense than for non-COPD controls (1.5-fold, $\mathrm{p}<0.0001$, fig 5A). KDR/Flk-1 and Flt- 1 expression were not changed in alveolar epithelial cells (fig 5B and C). VEGF expression was increased in intimal and medial VSM cells ( 1.5 and 1.7 -fold, $p<0.01$, fig $5 \mathrm{~A}$ ) of small pulmonary vessels in the alveolar region; the corresponding values for KDR/Flk1 were 2.0 and 1.8 -fold, respectively $(p<0.02$, fig $5 B)$. The expression of both KDR/Flk-1 and Flt-l was increased in endothelial cells of small pulmonary vessels in the lung parenchyma ( 1.7 and 2.1-fold, respectively, $\mathrm{p}<0.001$, fig 5B and $\mathrm{C}$ ).

\section{Correlation between staining and clinical data}

We examined the relationship between $\mathrm{FEV}_{1}$ values of patients in both groups and the staining scores of VEGF, Flt-1, and KDR/Flk-l in the investigated areas. In the bronchial airways $\mathrm{FEV}_{1}$ values were inversely correlated with VEGF staining scores in the mucosal microvasculature $(r=-0.65 ; \mathrm{p}<0.001$, fig $6 \mathrm{~A})$ and ASM cells $(r=-0.45$; $\mathrm{p}<0.01$, fig $6 \mathrm{~B})$ if all subjects were analysed together. The VEGF staining scores in the bronchiolar epithelium $(r=-0.67 ; \mathrm{p}<0.001$, fig $6 \mathrm{C})$ and medial VSM cells of larger pulmonary arteries associated with the bronchiolar airways $(r=-0.50 ; \mathrm{p}<0.01$, fig $6 \mathrm{D})$ also showed an inverse correlation with $\mathrm{FEV}_{1}$ values from the total group. In addition, VEGF expression in the medial VSM cells was correlated with KDR/Flk-1 expression in the endothelium of the pulmonary arteries $(r=0.41 ; \mathrm{p}<0.01)$ as well as the smaller alveolar vessels $(r=0.48 ; \mathrm{p}<0.01)$. Furthermore, we found correlation for the expression pattern of KDR/Flk-1 and Flt- 1 in the endothelium of the pulmonary arteries $(r=0.67 ; \mathrm{p}<0.001)$ as well as in alveolar vessels $(r=0.80 ; \mathrm{p}<0.0005)$.

We also examined the correlation between the epithelial VEGF expression from the current study and epithelial TGF$\beta_{1}$ expression from one of our previous studies. ${ }^{20}$ In the bronchiolar epithelium Pearson's analysis revealed a significant positive correlation between the levels of VEGF protein and TGF- $\beta_{1}$ protein $(r=0.55 ; \mathrm{p}<0.004)$ and between VEGF protein levels and TGF- $\beta_{1}$ mRNA expression $(r=0.45$; $\mathrm{p}<0.02$ ). In the alveolar epithelium VEGF protein levels correlated significantly with TGF- $\beta_{1}$ mRNA expression only $(r=0.58 ; \mathrm{p}<0.002)$, but not with $\mathrm{TGF}-\beta_{1}$ protein levels $(r=0.31 ; \mathrm{p}<0.12)$. 

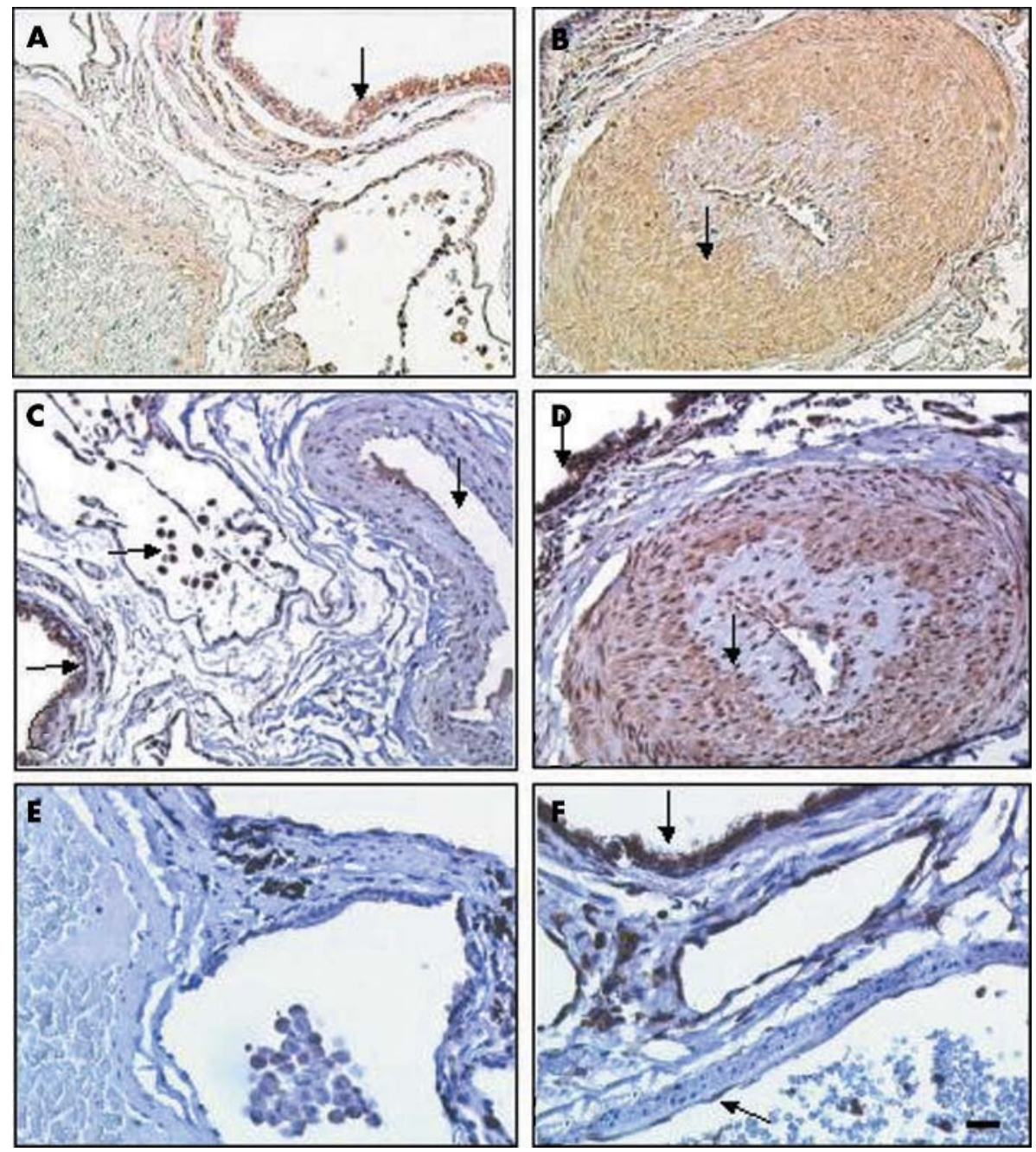

Figure 3 Immunohistochemical localisation of (A, B) VEGF, (C, D) KDR/Flk-1, and (E, F) Flt-1 in peripheral tissues from non-COPD (ex-) smoking subjects (A, C, E) and patients with COPD (B, D, F). Immunoreactive VEGF, Flt-1, and KDR/Flk-1 were localised in bronchiolar and alveolar epithelial cells, airway smooth muscle (ASM) cells, macrophages, and in endothelial and intimal/medial vascular smooth muscle (VSM) cells. Colour was developed with 3,3-diaminobenzidine tetrahydrochloride (DAB) as chromogen (brown colour) and counterstained with Mayer's haematoxylin. Arrows indicate sites of positivity for VEGF, Flt-1, or KDR/Flk-1. Original magnification $\times 100$; scale bar $=50 \mu \mathrm{m}$.

\section{DISCUSSION}

The results of this study show that COPD is associated with increased expression of VEGF in the bronchial, bronchiolar, and alveolar epithelium and in bronchiolar macrophages as well as ASM and VSM cells in both the bronchiolar and alveolar regions. KDR/Flk-1 and Flt-1 were increased in patients with COPD compared with non-COPD subjects in endothelial, intimal and medial VSM cells of the larger pulmonary arteries and of smaller calibre alveolar vessels. Interestingly, we observed a significant inverse correlation between VEGF and $\mathrm{FEV}_{1}$ in bronchial mucosal microvessels and ASM cells, bronchiolar epithelium, and medial VSM cells of the larger pulmonary arteries associated with the bronchiolar airways. TGF- $\beta_{1}$ staining in the bronchiolar epithelium also correlated with VEGF in the same patients as described in our previous study. ${ }^{20}$

Our results indicate that VEGF and its receptors Flt-1 and $\mathrm{KDR} /$ Flk- 1 are localised within the airways and vasculature in endothelial and epithelial cells as well as smooth muscle cells and, furthermore, on various inflammatory cells (predominantly macrophages). The localisation of VEGF and its receptors in the lungs of our patient groups is in agreement with earlier reports which described a similar staining pattern in human developing lungs, normal adult lungs, and emphysematous lungs. ${ }^{172728}$ In contrast to Kasahara et $a l^{28}$ who showed that VEGF and its receptor VEGF-R2 were decreased in total lung extracts of emphysematous lungs as measured by ELISA or western blot analysis, we found that the epithelial and endothelial cells in the alveolar spaces and in the most distal airways were intensely positive for VEGF and KDR/Flk-1 in patients with COPD. In our study the patients could be considered as having mild to moderate COPD whereas the lungs studied by Kasahara et al were solely emphysematous.

Our findings of increased VEGF expression in viable cell populations indicate in part a successful attempt to repair sustained damage, and perhaps a contribution to vascular remodelling and participation in the establishment and maintenance of the functional blood-gas interface, maturation, survival, and proliferation of capillary endothelial cells. ${ }^{29}$ In adult lungs VEGF and its receptor system may contribute to the maintenance of endothelial and epithelial cell viability in response to injury. ${ }^{31}$

Interestingly, immunoreactivity for VEGF in intimal and medial VSM cells and for Flt- 1 and KDR/Flk- 1 in endothelial cells of the pulmonary arteries and alveolar vessels was increased in patients with COPD. The highest levels of VEGF expression in the pulmonary vasculature were observed in 

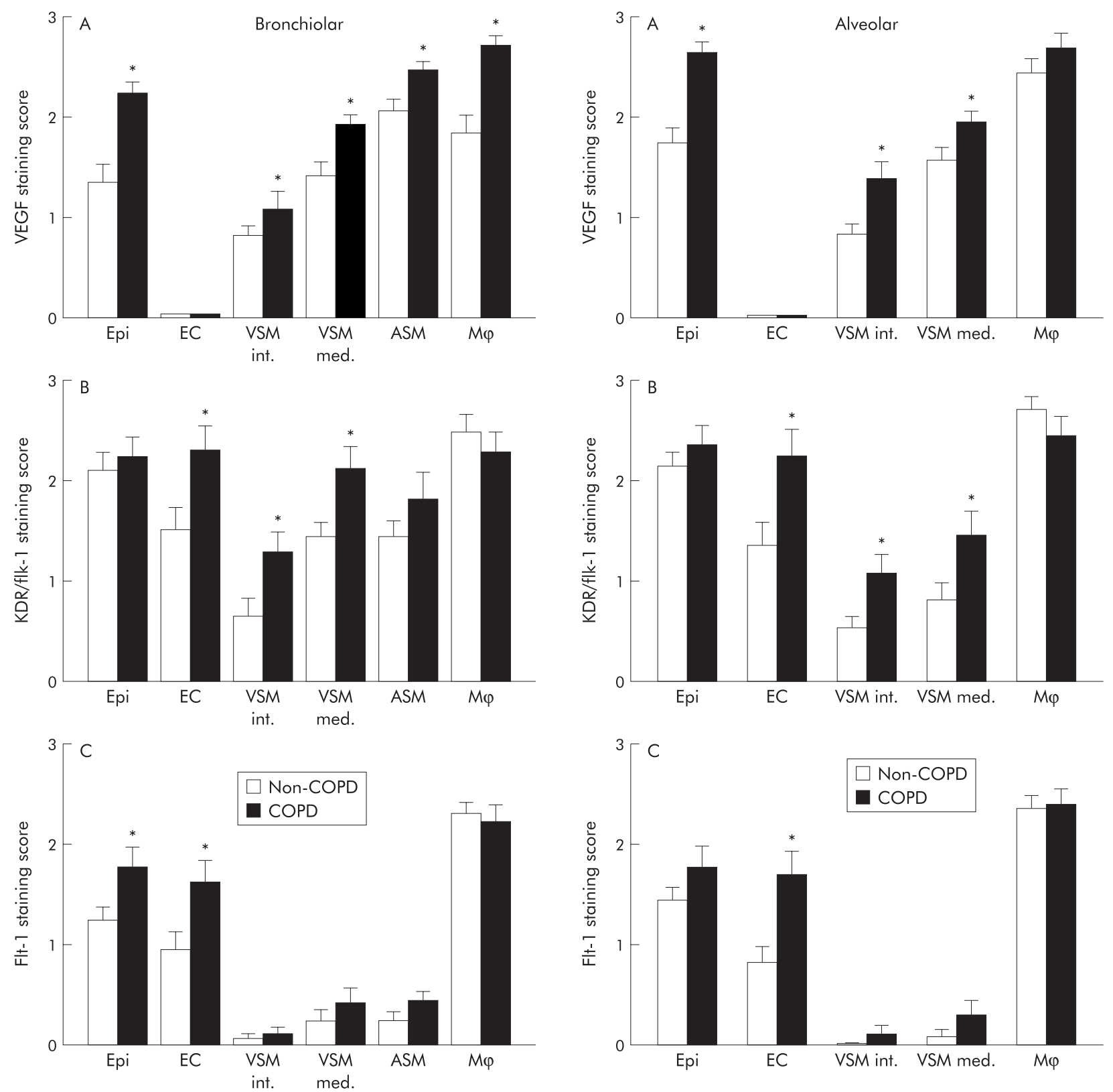

Figure 4 Expression of (A) VEGF, (B) KDR/Flk-1, and (C) Flt- 1 protein in different cell types in bronchiolar airways and associated pulmonary arteries using visual scoring. Open and closed bars represent mean data from subjects without and with COPD, respectively. Data are presented as mean (SE). Asterisk indicates a significant difference $(p<0.05$, Student's $t$ test) compared with non-COPD subjects. Epi, bronchiolar epithelium; EC, endothelial cells; VSM int, VSM med, intimal and medial vascular smooth muscle cells; $A S M$, airway smooth muscle cells; $M \phi$, bronchiolar macrophages.

the medial VSM cells and of KDR/Flk- 1 in endothelial cells of arteries with a diameter of approximately $200 \mu \mathrm{m}$, which are known to play an important role in pulmonary blood pressure regulation and vascular resistance. ${ }^{14} 30$ Pulmonary hypoxia and hypertension with increased sheer stress are pathophysiological conditions that have been shown to increase the expression of VEGF in VSM cells. ${ }^{13}{ }^{14}$ Blockade of KDR/Flk-1 is associated with obliterative endothelial cell proliferation in pre-capillary arterioles with abnormal vessel development and, at the same time, with induction of capillary endothelial and cell death by apoptosis, together leading to death in rat embryos similar to that seen in subjects with primary

Figure 5 Expression of (A) VEGF, (B) KDR/Flk-1, and (C) Flt-1 protein in different cell types in alveolar parenchyma and pulmonary vasculature using visual scoring. Open and closed bars represent mean data from subjects without and with COPD, respectively. Data are presented as mean (SE). Asterisk indicates a significant difference ( $p<0.05$, Student's $t$ test) compared with non-COPD subjects. Epi, bronchiolar epithelium; EC, endothelial cells; VSM int, VSM med, intimal and medial vascular smooth muscle cells; $M \phi$, bronchiolar macrophages.

pulmonary hypertension. ${ }^{13} 183132$ In a follow up study Tuder et $a l^{33}$ found that, after VEGFR-2 blockade, apoptosis predominated in areas of oxidative stress and apoptosis blockade by a broad spectrum caspase inhibitor markedly reduced the expression of markers of oxidative stress. ${ }^{33}$ Hypoxia, oxidative stress, and pulmonary hypertension are pathological features often seen in patients with advanced COPD, and increased VEGF expression may lead to increased or even abnormal proliferation of endothelial and VSM cells in pulmonary vessels. This suggests a potential role for this endothelial mitogen in peripheral angiogenesis and vascular remodelling, possibly in combination with other smooth muscle specific growth factors such as FGF-2, PDGF, and TGF- $\beta_{1} \cdot{ }^{12}{ }^{34-36}$ 

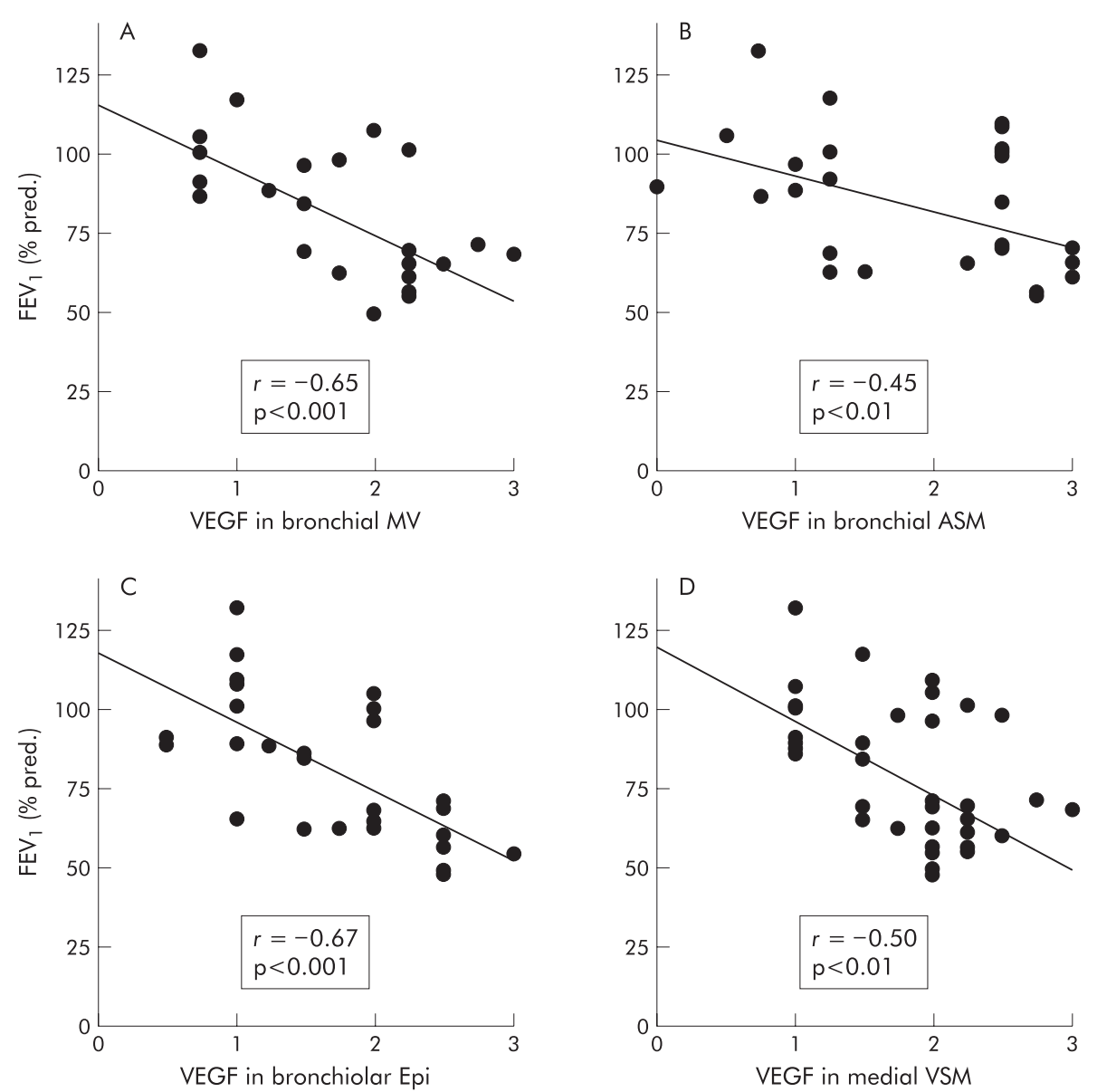

Figure 6 Correlation with $\mathrm{FEV}_{1}$ (\% predicted) of VEGF protein expression in (A) microvessels (MV) in the bronchial mucosa, (B) bronchial airway smooth muscle (ASM) cells, (C) bronchiolar epithelial (Epi) cells, and (D) medial vascular smooth muscle (VSM) cells of pulmonary arteries associated with the bronchiolar airways. Correlation was assessed for the combined patient groups (non-COPD and COPD). The correlation coefficient ( $r$ ) was obtained using linear regression (Pearson's) analysis.

We observed increased VEGF expression and unchanged Flt- 1 and KDR/Flk-1 expression in bronchiolar and alveolar epithelial cells as well as in ASM cells in patients with COPD. It has previously been reported that the expression of VEGF and receptor KDR/Flk-l can also be induced by stimuli such as hypoxia and oxidative stress in cells other than endothelial cells, such as epithelial and smooth muscle cells. ${ }^{33} 3738$ In a recent report Kanazawa and colleagues ${ }^{39}$ showed that VEGF levels in induced sputum were higher in patients with bronchitis and lower in those with emphysema than in normal controls. Moreover, VEGF levels in patients with bronchitis were inversely correlated with $\mathrm{FEV}_{1}$ values. Our data on the inverse correlation of VEGF levels in various airway and vascular cells is in agreement with this report. In our study subjects with COPD could not be subdivided into patients with either chronic bronchitis or emphysema alone. Furthermore, the nature of the human material examined (sputum) in the study by Kanazawa and colleagues is different from the lung tissue in which we immunohistochemically localised and quantified VEGF and its receptors.

Recent studies have indicated that VEGF expression is increased in bronchial and alveolar epithelial cells and is also induced in $\alpha$-SMA positive (myo)fibroblasts in bleomycin induced fibrosis in the rat and in human patients with pulmonary fibrosis, and that these fibrotic regions are densely populated by mast cells and macrophages with increased KDR/Flk-l expression. ${ }^{15}{ }^{17}$ We have shown previously that mast cells and macrophages are increased in bronchiolar airway epithelium and have reported increased expression of TGF- $\beta_{1}$ in bronchiolar and alveolar epithelial cells in patients with COPD. ${ }^{20} 21$ We found a significant correlation between VEGF expression in epithelial cells and TGF- $\beta_{1}$ expression published previously in the same patient groups, ${ }^{20}$ which suggests that the VEGF/Flk-1 systempossibly combined with TGF- $\beta_{1}$-represents a molecular link between inflammatory cell accumulation and proliferation of myofibroblasts.

The increased expression of VEGF and TGF- $\beta_{1}$ on bronchiolar epithelial cells and macrophages and the presence of KDR/Flk-1 and Flt-l suggest a mechanism of initiating and perpetuating fibrosis at sites of tobacco induced injury contributing to airway remodelling in COPD. Inhaled corticosteroids may decrease the levels of VEGF expression, ${ }^{40}$ but this was not the case in our study as none of the patients had received inhaled corticosteroid treatment except four who received corticosteroids perioperatively. Caution must be exercised in extrapolating the expression data based on only 14 patients in each group, but the trend for increased VEGF expression in bronchial airways and KDR/Flk- 1 in bronchial and bronchiolar airway smooth muscle could reach significance if more patients were included.

Taken together, these findings strongly suggest a role for VEGF and its receptors in airway and vascular remodelling, and thereby in the development of airway obstruction in COPD. At present our knowledge of airway and vascular 
remodelling during the development of COPD is far from complete. It is probable that many growth factors-including VEGF-play an essential role in the pulmonary and vascular viability and repair in response to tissue injury. Increased pulmonary VEGF expression in the airways, parenchymal lining, and small diameter pulmonary vessels in COPD may reflect a partly unsuccessful attempt to stimulate tissue repair mechanisms caused by tobacco induced injury.

\section{ACKNOWLEDGEMENTS}

The authors thank Drs J Stolk and J H J M van Krieken for their help in the analysis of the clinical data and pathology, respectively, and Mrs A Willems-Widyastuti for her technical assistance.

\section{Authors' affiliations}

A R Kranenburg, V K T Alagappan, H S Sharma, Department of Pharmacology, Erasmus MC, University Medical Center, Rotterdam, The Netherlands

W I de Boer, P J Sterk, Department of Pulmonology, Leiden University Medical Center, Leiden, The Netherlands

This study was supported in part by The Netherlands Asthma Foundation (grants \#97.73 and 95.49).

ARK and WIdB contributed equally to the work.

\section{REFERENCES}

1 Pauwels RA, Buist AS, Calverley PM, et al. Global strategy for the diagnosis, management, and prevention of chronic obstructive pulmonary disease. NHLBI/WHO Global Initiative for Chronic Obstructive Lung Disease (GOLD) Workshop summary. Am J Respir Crit Care Med 2001;163:1256-76.

2 Jeffery PK. Remodeling in asthma and chronic obstructive lung disease. Am J Respir Crit Care Med 2001;164:S28-38.

3 Jeffery PK. Lymphocytes, chronic bronchitis and chronic obstructive pulmonary disease. Novartis Found Symp. 2001;234: 149-61; discussion 161-8).

4 Saetta $M$, Turato $G$, Maestrelli $P$, et al. Cellular and structural bases of chronic obstructive pulmonary disease. Am J Respir Crit Care Med 2001;163:1304-9.

5 Cosio MG, Hale KA, Niewoehner DE. Morphologic and morphometric effects of prolonged cigarette smoking on the small airways. Am Rev Respir Dis 1980;122:265-71.

6 Lang MR, Fiaux GW, Gillooly M, et al. Collagen content of alveolar wall tissue in emphysematous and non-emphysematous lungs. Thorax 1994;49:319-26.

7 Wright $\mathrm{JL}$, Lawson L, Pare PD, et al. The structure and function of the pulmonary vasculature in mild chronic obstructive pulmonary disease. The effect of oxygen and exercise. Am Rev Respir Dis 1983;128:702-7.

8 Santos S, Peinado VI, Ramirez J, et al. Characterization of pulmonary vascular remodelling in smokers and patients with mild COPD. Eur Respir J 2002; 19:632-8

9 Magee F, Wright JL, Wiggs BR, et al. Pulmonary vascular structure and function in chronic obstructive pulmonary disease. Thorax 1988;43:183-9.

10 Peinado VI, Barbera JA, Abate P, et al. Inflammatory reaction in pulmonary muscular arteries of patients with mild chronic obstructive pulmonary disease. Am J Respir Crit Care Med 1999;159:1605-11.

11 Jeffery PK. Structural and inflammatory changes in COPD: a comparison with asthma. Thorax 1998;53:129-36.

12 Cross MJ, Claesson-Welsh L. FGF and VEGF function in angiogenesis: signalling pathways, biological responses and therapeutic inhibition. Trends Pharmacol Sci $2001 ; 22: 201-7$.

13 Voelkel NF, Cool C, Taraceviene-Stewart L, et al. Janus face of vascular endothelial growth factor: the obligatory survival factor for lung vascular endothelium controls precapillary artery remodeling in severe pulmonary hypertension. Crit Care Med 2002;30:S251-6.

14 Tuder RM, Flook BE, Voelkel NF. Increased gene expression for VEGF and the VEGF receptors KDR/Flk and Flt in lungs exposed to acute or to chronic hypoxia. Modulation of gene expression by nitric oxide. J Clin Invest 1995:95:1798-807.

15 Fehrenbach $\mathbf{H}$, Haase $M$, Kasper $M$, et al. Alterations in the immunohistochemical distribution patterns of vascular endothelial growth factor receptors Flk1 and Flt1 in bleomycin-induced rat lung fibrosis. Virchows Arch 1999;435:20-31.
16 Kasahara Y, Tuder RM, Taraseviciene-Stewart L, et al. Inhibition of VEGF receptors causes lung cell apoptosis and emphysema. J Clin Invest 2000;106:1311-9

17 Fehrenbach $\mathbf{H}$, Kasper $M$, Haase $M$, et al. Differential immunolocalization of VEGF in rat and human adult lung, and in experimental rat lung fibrosis: light, fluorescence, and electron microscopy. Anat Rec 1999;254:61-73.

18 Shehata SM, Mooi WJ, Okazaki T, et al. Enhanced expression of vascular endothelial growth factor in lungs of newborn infants with congenital diaphragmatic hernia and pulmonary hypertension. Thorax 1999:54:427-31.

19 de Boer WI, Sont JK, van Schadewijk A, et al. Monocyte chemoattractant protein 1, interleukin 8, and chronic airways inflammation in COPD. J Pathol 2000;190:619-26.

20 de Boer WI, van Schadewijk A, Sont JK, et al. Transforming growth factor betal and recruitment of macrophages and mast cells in airways in chronic obstructive pulmonary disease. Am J Respir Crit Care Med 1998;158:1951-7.

21 Grashoff WF, Sont JK, Sterk PJ, et al. Chronic obstructive pulmonary disease: role of bronchiolar mast cells and macrophages. Am J Pathol 1997:151:1785-90

22 Shi SR, Cote RJ, Hawes D, et al. Calcium-induced modification of protein conformation demonstrated by immunohistochemistry: What is the signal? J Histochem Cytochem 1999;47:463-70.

23 Kranenburg AR, De Boer WI, Van Krieken JH, et al. Enhanced expression of fibroblast growth factors and receptor FGFR-1 during vascular remodeling in chronic obstructive pulmonary disease. Am J Respir Cell Mol Biol 2002;27:517-25

24 Tuder RM, Groves B, Badesch DB, et al. Exuberant endothelial cell growth and elements of inflammation are present in plexiform lesions of pulmonary hypertension. Am J Pathol 1994; 144:275-85.

25 Gary Lee YC, Melkerneker D, Thompson PJ, et al. Transforming growth factor beta induces vascular endothelial growth factor elaboration from pleural mesothelial cells in vivo and in vitro. Am J Respir Crit Care Med 2002; 165:88-94.

26 Pertovaara L, Kaipainen A, Mustonen T, et al. Vascular endothelial growth factor is induced in response to transforming growth factor-beta in fibroblastic and epithelial cells. J Biol Chem 1994;269:6271-4.

27 Maeda S, Suzuki S, Suzuki T, et al. Analysis of intrapulmonary vessels and epithelial-endothelial interactions in the human developing lung. Lab Invest 2002;82:293-301

28 Kasahara Y, Tuder RM, Cool CD, et al. Endothelial cell death and decreased expression of vascular endothelial growth factor and vascular endothelial growth factor receptor 2 in emphysema. Am J Respir Crit Care Med $2001 ; 163: 737-44$

29 Healy AM, Morgenthau L, Zhu X, et al. VEGF is deposited in the subepithelial matrix at the leading edge of branching airways and stimulates neovascularization in the murine embryonic lung. Devel Dyn 2000;219:341-52.

30 Tuder RM, Chacon M, Alger L, et al. Expression of angiogenesis-related molecules in plexiform lesions in severe pulmonary hypertension: evidence for a process of disordered angiogenesis. J Pathol 2001;195:367-74.

31 Taraseviciene-Stewart L, Kasahara Y, Alger L, et al. Inhibition of the VEGF receptor 2 combined with chronic hypoxia causes cell death-dependent pulmonary endothelial cell proliferation and severe pulmonary hypertension. FASEB J 2001; 15:427-38.

32 Hirose S, Hosoda Y, Furuya S, et al. Expression of vascular endothelial growth factor and its receptors correlates closely with formation of the plexiform lesion in human pulmonary hypertension. Pathol Int 2000;50:472-9.

33 Tuder RM, Zhen L, Cho CY, et al. Oxidative stress and apoptosis interact and cause emphysema due to vascular endothelial growth factor receptor blockade. Am J Respir Cell Mol Biol 2003;29:88-97.

34 Warburton D, Schwarz M, Tefft D, et al. The molecular basis of lung morphogenesis. Mech Dev 2000;92:55-81.

35 Singh TM, Abe KY, Sasaki T, et al. Basic fibroblast growth factor expression precedes flow-induced arterial enlargement. J Surg Res 1998;77:165-73.

36 Carmeliet P. Mechanisms of angiogenesis and arteriogenesis. Nat Med 2000;6:389-95.

37 Christou H, Yoshida A, Arthur V, et al. Increased vascular endothelial growth factor production in the lungs of rats with hypoxia-induced pulmonary hypertension. Am J Respir Cell Mol Biol 1998;18:768-76.

38 Compernolle V, Brusselmans K, Acker T, et al. Loss of HIF-2alpha and inhibition of VEGF impair fetal lung maturation, whereas treatment with VEGF prevents fatal respiratory distress in premature mice. Nat Med 2002;8:702-10.

39 Kanazawa H, Asai K, Hirata K, et al. Possible effects of vascular endothelial growth factor in the pathogenesis of chronic obstructive pulmonary disease. Am J Med 2003; 114:354-8

40 Asai K, Kanazawa H, Kamori H, et al. Increased levels of vascular endothelial growth factor in induced sputum in asthmatic patients. Clin Exp Allergy 2003;33:595-9. 